Article

\title{
The Dilemmas Selection of Anti-Crisis Economic Strategy in Forestry and the Wood-Based Sector in the Perspective of a Long-Term Pandemic Threat - the Case of Poland
}

\author{
Leszek Wanat ${ }^{1,2, *}$, Rafał Czarnecki ${ }^{2}$, Władysław Kusiak ${ }^{3}$, Elżbieta Mikołajczak ${ }^{1}$, Łukasz \\ Sarniak ${ }^{1}$, Jan Sikora ${ }^{4}$ and Marek Wieruszewski ${ }^{3}$ \\ 1 Faculty of Economics and Social Sciences, Poznan University of Life Sciences, Wojska Polskiego 28, 60-637 \\ Poznan, Poland; leszek.wanat@up.poznan.pl (L.W.); elzbieta.mikolajczak@up.poznan.pl (E.M.); \\ lukasz.sarniak@up.poznan.pl (Ł.S.); \\ 2 Faculty of Computer Science and Visual Communication, Collegium Da Vinci, Kutrzeby 10, 61-719 \\ Poznan, Poland; leszek.wanat@up.poznan.pl (L.W.); rafal.czarnecki@cdv.pl (R.C.); \\ 3 Faculty of Wood Technology, Poznan University of Life Sciences, Wojska Polskiego 38/42, 60-627 Poznan, \\ Poland; wladyslaw.kusiak@up.poznan.pl (W.K.); marek.wieruszewski@up.poznan.pl (M.W.); \\ 4 Department of Regional Policy, Faculty of Economics and Management, University of Zielona Gora, \\ Licealna 9, 65-417 Zielona Gora, Poland; j.sikora@wez.uz.zgora.pl (J.S.); \\ * Correspondence: leszek.wanat@up.poznan; ORCID: https://orcid.org/0000-0002-1166-9258 (L.W.)
}

\begin{abstract}
Forestry and the wood-based sector, including the wood industry, which is an important element of economic systems and a source of budget revenues for many countries in the world, found itself in the first quarter of 2020 in a situation of a serious threat of a prolonged crisis as a consequence of the pandemic. In this perspective, it is necessary to review existing sector strategies and look for new solutions to ensure first survival, then functioning and finally development of entities forming the wood market. In the scientific research, which is the subject of this work, an attempt was made to multi-criteria analysis of the selection of the optimal anti-crisis strategy for actors from forestry and the wood-based sector in the face of a pandemic. Preparatory studies were conducted on the example of Poland, where both forestry and the wood industry belong to the dominant sectors of the economy, conducting them at the turn of March and April 2020. The research was referred to the primary wood raw material market in Poland, which is the main link in the value chain, created first by the dominant owner: Państwowe Gospodarstwo Leśne "Lasy Państwowe" - the "State Forests" National Forest Holding (SFNFH), and then forest service entrepreneurs, to entities representing the wood industry. The work uses a concept modified for the purposes of the author's research scenario, based on the method of multi-criteria hierarchical analysis AHP (Analytic Hierarchy Process). The best possible decision was to be searched that would allow the selection of the optimal anti-crisis strategy for enterprises - actors of the sector concerned. Based on the collected results and their expert discussion, recommendations for sectoral policy for forestry and the wood-based sector were then formulated. The proposed solutions are located against the background of a dispute between the concept of institutional intervention and a model taking into account the effects of market factors. The work is both cognitive (optimization and adaptation of the research method) and practical up-to-date. An accurate development strategy for forestry and the wood-based sector is urgently needed and necessary to implement as quickly as possible.
\end{abstract}

Keywords: forestry; wood-based sector; anti-crisis economic strategy; pandemic crisis; Analytic Hierarchy Process; Poland

\section{Introduction}


Perhaps it was necessary to find ourselves in an exceptional situation, previously unprecedented on a global scale, to make sure that forests perform in the culture and economy of each state and nation specific functions that are integrally connected with each other. These include both natural (also called protective or ecological), social (including cultural) and productive (economic) functions. Indeed, the share of individual forestry functions in the economy of specific countries may vary. However, this does not change the perspective of any wood-based economic activity for which consideration of coexistence of economic, ecological and strictly industrial issues seems to be a necessity. It is worth noting that the concept of "sustainable development" comes directly from forest management. Hans Carl von Carlowitz [1, 2] defined the concept of economic activity in forestry, consisting in acquiring the appropriate, i.e. only the amount of industrial wood that can be reconstructed by means of natural forest regeneration. The von Carlowitz idea was propagated in 19th century Europe as Sustained Yield Forestry [3]. Thus, the concept of "sustainable" made an extraordinary career, and not only in forestry, becoming the key word in the theory of sustainable development [4, 5]. Will the perspective outlined in this way prove sufficient? Maybe it is about more than just mathematical "balance"? Critical discussions about the traditional model of the economy are underway, waging a classical dispute between the model with a strong institutional profile (Keynes model and derivatives) $[6,7,8,9,10]$ with the classic market model (Friedman model and derivatives) $[11,12,13,14,15]$. Is there a compromise that could show the way of coexistence, taking into account the specific, often very individual development ability of each of the market participants? At the same time, one sees the need to search for new development paths, rediscovering the so-called green development path [16, 17]. Important questions are posed about the social responsibility of subsequent generations, using the resources of the green economy as if on credit. A possible dispensation from this human responsibility for constant concern for the state of natural resources, including forests $[18,19,20]$, and for the quality of life of future generations is no longer acceptable today.

\section{Starting Point - Competitive Situation}

In a completely new perspective, in Q1 2020, in view of the various currently identified symptoms of crisis crises, the forest-and wood-based sector in Poland was analyzed. They were looking for answers to the question of how entities should represent the sector from traditional forestry to the timber industry should face the threat of a global crisis. The general unknown is the time factor above all. So, the next questions are: how long will the epidemic debt last? how will the market change when exposed to irregular and asymmetrical factors? What will be the consequences of these changes for wood-based market participants? So what will this new market be like, created by foresters, entrepreneurs and users of wood and wood products? Will it be a relationship market whose essence is not only the exchange of goods and services, which does not operate "in the singular", but operates in the meta-perspective of cooperation and even coopetition? Perhaps such a market will best explain not only the law of balance, not anonymity, but personalization, expressed by the key word 'we'.

The starting point for the designed research is the current state and special features of forestry and wood-based sector in Poland. The area of forests in Poland in 2018 was 9.46 million ha, which represents $30.9 \%$ of the total area - in \% of forest land in land area. The area of forests per capita is 0.241 ha (forest area per capita in ha 0.241 ), respectively. In turn, Poland's forest cover amounted to $29.6 \%$ in the same period (forest cover in\%). It is worth noting that in the eighteenth century, forest cover (forest cover), in relation to the then historical borders of Poland was almost $40 \%$ [21].

$76.9 \%$ of the total forest area is managed by the State Forests Board - the "State Forests" National Forest Holding (SFNFH). Another 19.3\% of the area are private forests, and the remaining 3.8\% are, among others forests in national parks and ownership of communes. All this proves the significant potential of forest management, which places Poland in the 7th place in the European Union. In addition, 45.6 million $\mathrm{m}^{3}$ of wood is obtained annually in Poland. At the same time, Polish wood resources in 2017 amounted to 2.03 billion $\mathrm{m} 3$ of thicknesses, the average volume of $286 \mathrm{~m}^{3}$ of thicknesses per 1 ha, and timber harvesting was $73.5 \%$ of the annual current increase. Forestry 
together with the wood industry creates a strong wood-based economy sector. This sector employs approximately 350 thousand people, which represents almost $3 \%$ of the total employment in the whole economy. The wood-based industry, also including related parties, generates over 2.5 percent. Poland's GDP and around $11 \%$ of value added in manufacturing, with a value approaching up to USD 10 billion a year. It consists of, among others, a strong furniture industry, producers of woodbased panels: chipboard, fiber and others, producers of cellulose and paper [21, 22].

At the same time, the sector's strength lies in entrepreneurs producing sawn timber, wooden floors, pallets, garden architecture, wooden structures, wooden houses and many other wood-based products. Poland is the largest EU producer of wooden floors, HDF / MDF boards and garden equipment, the fourth furniture manufacturer, the second producer of chipboards, the eighth producer of sawn timber. It is worth noting that the majority of sawmill entrepreneurs (elemental wood processing) and furniture manufacturers that make up this result belong to the groups of small and medium-sized enterprises. Finally, it should be added that the Polish wood industry is almost entirely based on domestic timber resources obtained from Polish forests [22].

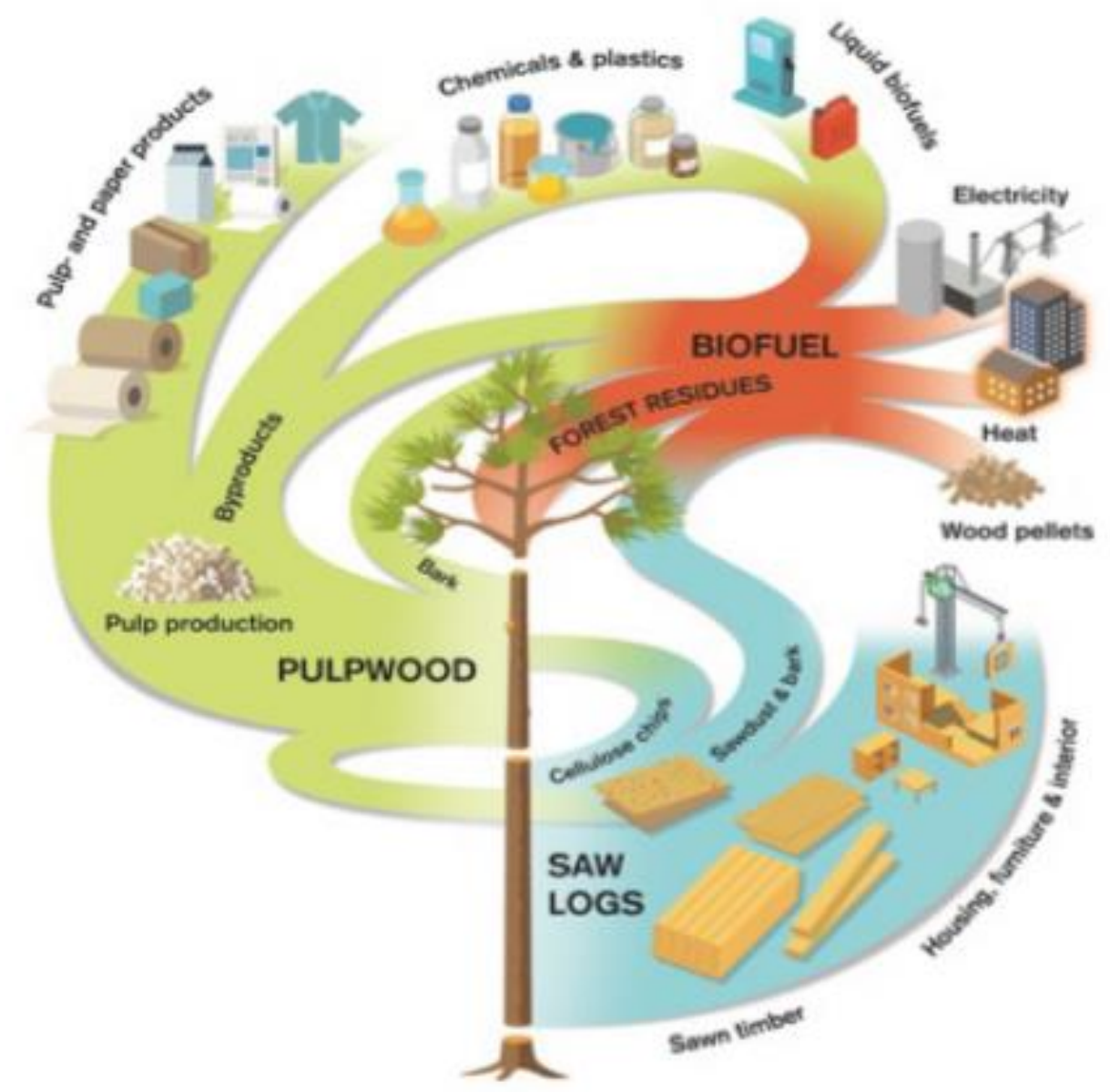

Figure 1. The main segment of the forest-wood value chain. Sub-sector meso-orientation: blue-greenred, based on the graphic concept proposed by Meskin and Borkowski [23] (p. 30).

Source: Meskin, A.; Borkowski, P. State Forests in the Baltic Sea Region: Where experience meets challenges and future opportunities, In Liuhto, K. (eds.). The forest industry around the Baltic Sea region: Future challenges and opportunities, BSR Policy Briefing series, 1, 2020, p. 30, Centrum Balticum Foundation [23]. Available online: https://www.centrumbalticum.org/files/4638/BSR_Policy_Briefing_2020.pdf, accessed: 21 April 2020. 
The Polish forestry and wood sector is characterized by a specific market organization. This is a typical model for an institutional structure based on a natural monopoly [16, 17]. The wood market is complementary economic sectors: forestry and wood industry. The structure of the sector is also determined by the market environment: institutional, business, social, demographic and cultural. It should be emphasized that mutual relations of wood market participants, especially the wood raw material market (primary segment), are only shaped to a small extent by the market mechanism [22]. It results both from the ownership structure of Polish forests (dominant state ownership), from real, objective barriers to entering the sector, but also from the wood sales model, in which only some aspects are subject to market law [23, 24]. However, this does not change the relationship in the forestwood value chain, initiated by raw forestry (resource management and protection), then through forest services (related primarily to the acquisition of wood raw material and its transport), to industrial, commercial processing of wood by the main branches of the wood industry and various production and service enterprises based on wood (see Figure 1) [23]. Of course, we are talking only about the first (primary) module of the entire chain, which can successfully fit into the circular economy model, integrating all stages all together: the blocks of the chain the stronger, the more human-oriented, anthropocentric.

Because the development of the forest-wood sector in Poland, based primarily on the wealth of forest resources, is not programmed by the primacy (or dominance) of market competitiveness, space for "new" development factors is opening up [25, 26]. This applies in particular to cross-sectoral cooperation and coopetition, and even to a kind of "symbiosis" of green economy entities and its partners [27, 28]. It should be noted that forestry and the wood industry are an important element of economic systems and, as a result, a source of budget revenues for many countries in the world. The group of these countries also includes Poland, located in Central Europe, and more broadly in the economic zone known as the EMEA Region [29].

It would seem that on the example of Poland one can attempt to look for solutions only of a local or regional nature. Meanwhile, as noted in the economic literature [30, 31, 32, 33], the use of similarity criteria, and thus the extension of observations made, also other economies with a similar structure, or at least based on a similar value chain in forestry, provides an opportunity to formulate broader general applications [34, 35].

Like many industrial sectors, also the wood-based sector found itself in Q1 2020 in a serious threat of a prolonged crisis. This threat is not only an obvious consequence of the pandemic state, but also the effect of subsequent institutional and market decisions resulting from this state. Only this information indicates the need to revise current sector strategies, followed by business models and market structures. This revision process requires urgent search for new solutions [36]. Their goal seems to be firstly the survival and preservation of the status quo, then at least relatively proper functioning, and finally the development of enterprises and all actors involved in the wood market. For these reasons, an attempt was made in this study to seek an adequate anti-crisis strategy addressed to various partners from the forestry and wood-based sector, in fact participating in this sector, and necessarily operating in the realities of numerous restrictions resulting from the epidemic threat.

\section{The Concept, Resources and Research Methods}

\subsection{The Concept of Research}

Uncertainty, as a category characterizing decision-making situations, is a common phenomenon in economic policy. In addition, in relation to the wood-based sector, it is characterized by a relatively high level of complexity, typical of systems based on natural management [37]. In the face of uncertainty, the decision-maker can take the following attitudes:

- intuitive: making decisions based on intuition,

- experimental: deciding based on measurement, experiment or modeling, using the available tools of the scientific workshop, including game theory (for example, strategic games, when there are more decision-makers in a decision-making situation who influence the final result), or theories of 
making decisions in conditions of uncertainty (especially in a situation where the effects of decisions and actions taken as a result of them are decided by nature - the so-called play with nature),

- active: attempting to reduce uncertainty.

This work focuses on the problem of reducing uncertainty as one of the perspectives that allows to reduce the risk of decisions taken in a crisis situation. The main purpose of the work was an attempt to identify and evaluate a relatively simple, practical method of reducing uncertainty in sectoral policy, based on the example of forest- and wood-based sector in Poland. The selected sector, as one of the leading in the Polish economy, has found itself in a situation where it is necessary to choose adequate anti-crisis strategies, i.e. immediate economic decisions of various scales, in the face of a serious long-term threat of the effects of a global pandemic. An alternative to a possible abandonment of any decisions may be widespread bankruptcy and liquidation of many enterprises, jobs, and, as a result, a threat to economic, social and ecological security for the state, economy and people.

For verification purposes, a hypothesis was adopted, which assumed that it is possible to choose the optimal anti-crisis strategy adequate to the identified market situation of the participating entities (stakeholders). Of course, this choice should take into account different perspectives of interest and actions of key participants (actors) of the examined industry market, rather reluctant under normal conditions to a strong consensus. In addition, it was assumed that as a consequence of the use of a method as simple as possible, understood by decision-makers, it is possible to at least partially reduce the level of uncertainty in the decision-making process (tantamount to obtaining much greater reliability of the response than when using the complicated method, sometimes requiring not only industry but also professional experience analytical knowledge from study participants). Such a hypothesis was verified on the example of the analysis of suggested strategic decisions proposed by participants (actors) of the primary wood raw material market in Poland. Based on the deliberately selected key criteria and the diverse, leading strategies corresponding to these criteria, potential decisions of market participants were identified using the tools proposed by the diagnostic survey method. The collected opinions of market actors, coded within the range of selectable decisions, were then verified using the method of multi-criteria hierarchical analysis (AHP), also referring to the general rules for making economic decisions [38], including the Pareto principle [39].

\subsection{Methodical Basis of Research}

The starting point for multi-criteria analysis is the construction of a decision model, which in the case of this method is a hierarchical structure. The hierarchical model allows to gather in one place all factors affecting the decision goal. This avoids the difficulties pointed out by one of the precursors of modern thinking about the effects of the decision-making process - Benjamin Franklin [40]. He noticed that the difficulty of making decisions results from a limited perspective in the analysis process, because at the same time there are no key arguments "for and against" a particular solution [38]. A properly constructed hierarchy allows not only to see the most important (though we would like to say: all) aspects of the decision problem, but also to organize them into homogeneous sets of comparable elements.

It is worth noting that the stage of construction of the hierarchical model is taken for granted in the literature [41]. At the same time, relatively little attention was paid to the process of defining and grouping its elements. It should be emphasized that building a hierarchical model, requiring the involvement of a large amount of time and resources, may be doomed to failure when the participation of experts - specialists, practitioners from various segments of the market under investigation is excluded. This is not so much about formal decision makers as about those who actually participate in market processes, who, if you can say so, "live what they do". It is they who, due to the obvious limitation in complementing the conditions of statistical representativeness of the sample, can decide and even prejudge the value and reliability of the information obtained. Validating the correctness of the hierarchical structure completes the first step of the research scenario. Then, the hierarchical model is subjected to analysis, consisting in comparing all pairs of elements created within individual groups, using the fairly commonly used so-called a bipolar, nine-point scale, proposed by Thomas L. Saaty, a professor at the University of Pittsburgh [42, 43]. Various 
aspects of the practical application of the aforementioned nine-point fundamental scale of comparisons, the principles of creating sets of pairs of elements within a hierarchical structure, and practical issues related to the construction of the questionnaire, including the way of presenting and formulating questions, are quite widely discussed in the literature $[44,45,46]$. For the purposes of this study, generally accepted principles have been applied, adapting the procedure to the specifics of the industry market under investigation.

Another important element of research is the procedure for obtaining primary data from experts (respondents). Therefore, issues regarding the selection of respondents for research, obtaining grades from them based on comparisons of created pairs of elements and the rules for entering the results of these grades into the results matrix sheet were precisely defined. It should be added that obtaining information for the analysis of the hierarchical model is the stage that can generate the most problems in the whole process. Sometimes the problem of non-compliance of assessments causes that there may be premises for questioning the credibility of the results obtained.

The next stage of AHP is the calculation part, consisting in mathematical determination of the value of weighting factors (priorities, weights). In principle, four different ways of calculating priorities are listed in the literature: using specialized software, as well as using matrix calculus, geometric mean and arithmetic mean.

The determination of the weighting values does not end the analysis. For each comparison matrix, an analysis of its quality is carried out, i.e. verification of compliance (logic), which reflects the reliability of information indicated by experts (respondents). The measure of this compliance is an additional parameter called the consistency ratio (CR). Sometimes, in addition to measuring compliance, sensitivity analysis is also carried out. On this basis, the sensitivity of the values of the weighting factors obtained to the changes in individual assessments is checked [46].

After compiling the correct values of weighting coefficients, the next step is to aggregate the results in the case of group decisions (often reconciling the initially divergent preferences). AHP proposes the following ways of aggregating assessments: aggregation of individual judgments (AIJ) and aggregation of individual priorities (AIP). AIJ takes place at the stage of making comparisons in pairs and is used when the group makes a decision together, in the same place and time, while AIP consists in combining the values of weighting factors from independent experts (respondents). The selection of the results aggregation method therefore depends on how the data is obtained.

The final stage of using the AHP method is to discuss the results, compile conclusions and try to formulate recommendations for the optimal decision [43]. The research process illustrates well the management dilemmas that are based on continuous decision making, increasingly complex and multifaceted. Therefore, the ability to practically apply an adequate method is one of the most important challenges of a modern manager.

Why was the AHP method chosen? Making complex decisions usually requires a precise approach, consisting of considering successively each aspect ("criteria") of a given problem and determining the relative weight of these criteria. This approach forms the basis of many decision support methods, and is termed the term: Multiple-Criteria Decision Analysis (MCDA) [38]. As Hoghart (1987) noted, "our mind is unable to comprehend all the information that makes up the decision problem, and in particular those elements that are mutually exclusive. That is why all judgments based only on intuition are insufficient - they need support" [37]. Many methods available today are based on complex formal procedures and require the use of complex calculation procedures or numerical methods. Therefore, various methods are selected from the MCDA collection, such as: ELECTRE, PROMETHEE \& GAIA, MACBETH, TOPSIS, UTA, and VDA. Tools that refer to the AHP (Analytic Hierarchy Process) and ANP (Analytic Network Process) analysis are also increasingly used [47].

A research approach based on hierarchical analysis was proposed in the 1970s by the aforementioned Thomas L. Saaty [42]. The method would probably not have been developed and improved if Professor Saaty, as a lecturer at Wharton School, was not bothered by the lack of a practical solution supporting the decision-making process and setting priorities. The effect of this scientific "anguish" has become a relatively simple tool, supporting decision-makers in making 
complex decisions [48]. In addition to numerous recommendations from other researchers [49, 50, 51, 52], as well as flexibility and universality, this very advantage of the AHP method and the possibility of author's adaptation to the specific test conditions, decided on its choice for the purposes of this study.

\subsection{Data Sources and Research Materials}

The study was conducted on the example of Poland (spatial scope), where both forestry and the wood industry belong to important, and in some aspects even dominant sectors of the economy. The study was of a pilot nature and was carried out at the turn of March and April 2020 (time range). In terms of subject, the study was related to participants of the primary wood raw material market in Poland. This market segment is the basic link in the forest management value chain (it appears as one of the elements illustrated in Figure 1) [23]. This chain is created first by the dominant owner: The State Forests National Forest Holding, and then forestry service entrepreneurs, to entities representing the wood industry, and in this case elemental wood processing plants. The spatial structure of the study was referred to the administrative regional division of the State Forests in Poland. It separates the territorial areas of seventeen Regional Directorates of State Forests (RDSF), aggregating a total of 430 forest districts. This structure only partly overlaps with the official, administrative division of Poland into regions (so-called local government voivodships). The work uses the first division, reflecting the structure of Polish forestry, illustrated in Figure 2 [24].

The concept of hierarchical analysis modified for research purposes was used. The research scenario was built based on the methodological assumptions of AHP (Analytic Hierarchy Process) multi-criteria hierarchical analysis, however, "imposing" them on the specific structure of a selected segment of the sector under investigation $[44,53]$. The best possible decision was sought: institutional or market, allowing selection of the optimal anti-crisis strategy for all participants of the industry market (scope). The study first used expert analysis to identify key factors affecting the real competitive situation of enterprises in the Polish wood-based sector. In connection with these factors, at the same time, possible strategies for action, both market-oriented and institutional, were sought. This selection allowed for the construction of a strategy matrix associated with intentionally selected influence factors. This set was then verified by means of a diagnostic survey. To a selected group of professional representatives of state forestry, forest services and wood industry entrepreneurs representing all institutionally designated forest areas in Poland (Regional Directorates of State Forests, marked abbreviations as above - RDSF), a professional questionnaire was addressed, based on it was conducted remotely, due to pandemic conditions, in-depth interviews. The answers obtained were collected and ordered. Then they were evaluated by multi-criteria hierarchical analysis (adapted AHP).

The research was looking for the optimal strategy possible, adequate to the current economic situation, which would help at least reduce the impact of negative factors of the post-pandemic crisis. Therefore, questions were asked, demanding not only a professional but specific answer, and consequently a rational economic decision. Indeed, it was decided to first indicate, in the course of expert analysis, the main possible directions of action (strategy matrix). The proposed solutions are located against the background of a dispute between the concept of institutional intervention and a model taking into account the impact of market factors. The research was started with the awareness that the indication of an adequate development strategy for the forestry and wood-based sector is urgently needed not only on theoretical grounds, but as an example possible for real implementation. 


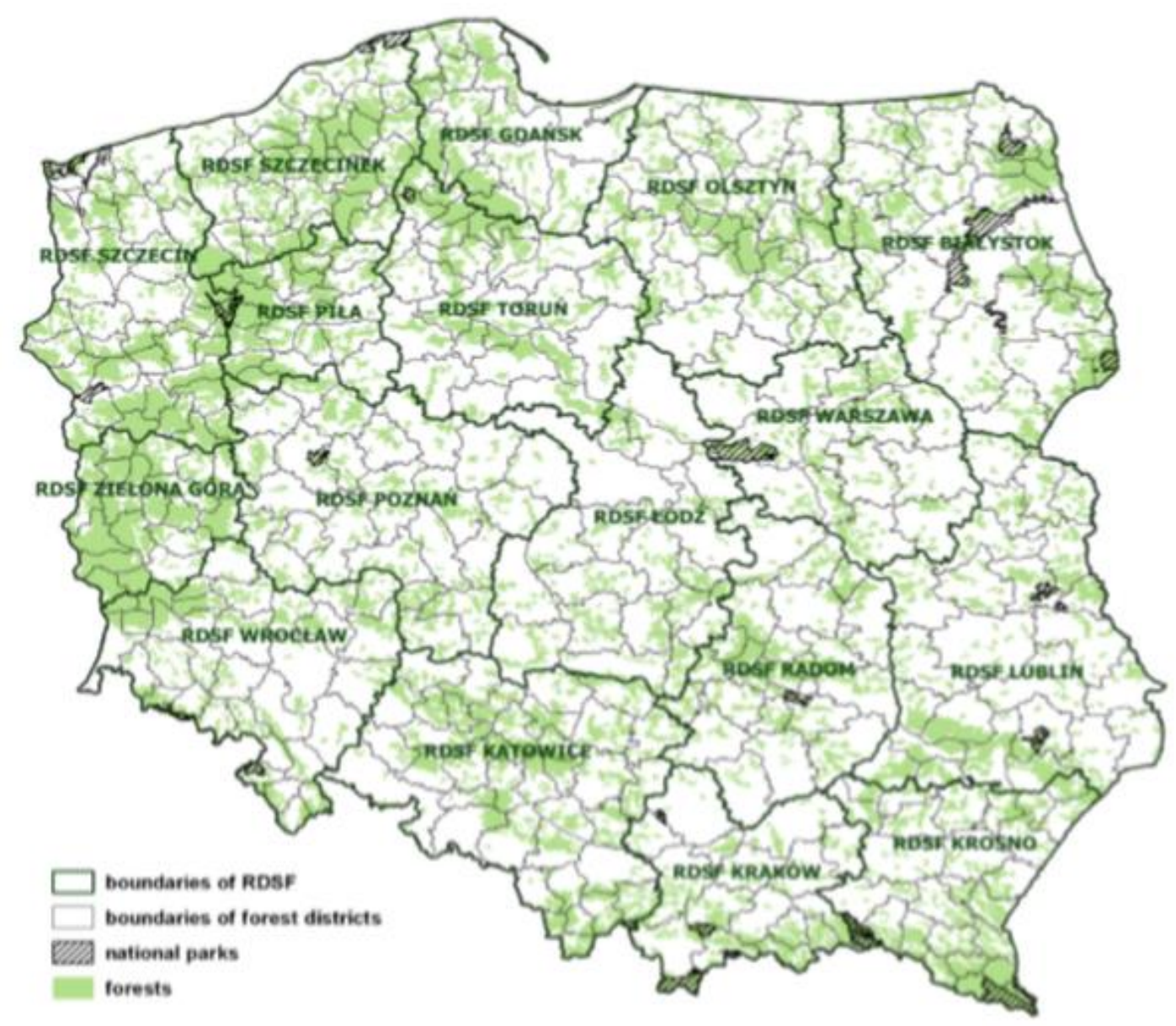

Figure 2. Forests in Poland against the background of administrative borders of the Regional Directorates of the State Forests (territorial division into 17 RDSFs) and their forest districts, including the location of national parks (2018), based on Gołos and Hilszczański, and Forest Research Institute [24] (p. 40).

Source: The map chart lists in turn: the boundaries of RDSF, the borders of the forest districts, national parks and forests, based on: Gołos, P.; Hilszczański, J. Social and economic importance of the forestry and wood sector in Poland, In Liuhto, K. (eds.). The forest industry around the Baltic Sea region: Future challenges and opportunities, BSR Policy Briefing series, No. 1, 2020, p. 40. Centrum Balticum Foundation. Spatial data based on: Instytut Badawczy Leśnictwa (Forest Research Institute), Poland, https://www.centrumbalticum.org/files/4638/BSR_Policy_Briefing_2020.pdf, accessed: 21 April 2020 [24].

The decision problem occurs when a person faces the choice of one of at least two possibilities. The choice he makes depends on the decision criteria, i.e. the factors that influence that choice. In this context, the concept of the so-called rational decision [54]. Each decision has its consequences. Some of them are assessed positively (through benefits), others negatively (through expenditure), while others remain neutral (or there is a lack of certainty as to their assessment). The key postulate of rationality is to choose those variants that take into account the right relationship between positive and negative effects. The problem then arises of determining the strength of these relationships. Usually, therefore, the simplest approach is used, reducing the assessment to a common denominator, which is a numerical measure that reflects the weight of individual criteria [53]. This "common denominator", i.e. an adequate decision-making measure, is determined using the AHP method, on the basis of which the author's research scenario was designed. 


\section{Research Scenario}

\subsection{Programming Research Stages}

Although different approaches can be found in the literature on the subject [55, 56, 57, 58], it seems justified to simplify the distinction in the process of hierarchical analysis of three basic levels of research (see Figure 3): identification of the decision problem (level 1), its structuring (level 2) and analysis (level 3) [59]. This process, finalized by analyzing the problem, closes the decision, i.e. the choice of the best solution. The whole can also be described in detail, distinguishing at least five research steps: problem hierarchy (research step 1), problem decomposition (research step 2), evaluation of the examined criteria by pair comparison (research step 3), determination of mutual preferences (weights) related to criteria (factors) and decision variants (research step 4), and finally choosing the optimal decision based on the result of the problem analysis (research step 5).

Of course, when designing the author's research scenario, it is possible to distinguish main stages or specify them, according to the specific conditions of the study. In addition, solving a decision problem is a broader concept than the decision making process itself. It covers the implementation, i.e. the implementation of the decision (implementation of the chosen solution) and assessment of its effects (evaluation). However, the work focuses on this first perspective, aiming at identifying the optimal decision (choice of anti-crisis strategy) and the ability to make it.

\subsubsection{Research Step 1}

Research Step 1, i.e. hierarchy of issues, includes a detailed description of the problem, identification of study participants, determination of the main goal and expected results. The purpose of the work was to look for anti-crisis strategies necessary for implementation in the forestry and wood-based sector in Poland, in view of the serious long-term risk of negative economic effects of a global pandemic for entities participating in the studied sector. The hypothesis was verified, in which it was assumed that it is possible to choose the optimal strategy, adequate to the identified market situation of entities creating the primary wood market.

Representatives of three subsectors, forming the primary wood market segment in the forest-wood value chain, were invited to the study (subject scope):

- in the first group: foresters (here: competent, professional employees of the State Forests, directly related to the practice of forest use),

- in the second group: forest-services entrepreneurs (as entities directly connecting economic relations of forestry with the wood industry, directly participating in the process of obtaining wood raw material, including cutting, skidding and transporting wood),

- in the third group: representatives of woodworking plants (primarily practitioners involved in the management of elemental wood processing plants).

In the spatial scope, the selection of professional study participants was diversified, assuming a minimum condition for obtaining answers from at least 3 representatives of each of the industry regions, designated by the territorial boundaries of 17 Regional Directorates of State Forests, including a minimum of one representative of each of the sub-sector groups. To this end, selected 300 industry representatives (forestry and wood-based sector) were invited to research, giving them the status of professional experts. In fact, 179 positive responses were obtained from all subsectors (consent to participate in the study), on the basis of which, based on the author's own questionnaire, in-depth interviews were conducted with each of the experts by means of remote communication. This allowed for the efficient conduct of the study, and all doubts and nuances related to the specificity of the AHP method were clarified at this stage by the research team [59]. This avoided many errors and obtained relatively high reliability of results. Although interviews were conducted with specific individuals, their responses were given anonymous status. In this way, the influence of emotional factors, sometimes determining the decision-making process in situations where 
anonymity cannot be preserved, has been eliminated. In fact, after rejecting the incomplete and containing questionnaires with the characteristics of "outliers" and inconsistent, the required minimum data was adopted for analysis. Thus, 103 sets of answers were added to the base of the spreadsheet, 51 from each group corresponding to selected subsectors (forestry, forestry services, wood industry), and 3 sets for each of 17 territorial units - Regional Directorates of State Forests in Poland. Experts, also referred to as respondents for the needs of the survey, also indicated the headquarters of their activity, also referring to the territory of Polish self-government voivodships (there are 16 of them, and their area does not cover directly with the territory of the forest management), and in the case of enterprises also their size (broken down for micro, small and medium and large companies). It is worth emphasizing the conscious, real participation in the analysis of the decision-making process of group representatives, rather reluctant in normal to decisive conditions. a simple consensus.

\subsubsection{Research Step 2}

Research Step 2, i.e. problem decomposition, consists in isolating the overarching goal, selection of key factors (impact criteria) as part of expert pre-analysis, and at the same time, in an analogous procedure, selection of considered decision variants (optimal strategies). It is the verified variants (decision options) that reflect the degree of implementation of the objective function, identified for each level of the hierarchical model being analyzed.

The hypothesis set out at the beginning of the study was verified in the process of analyzing suggested strategic decisions (decision options), which should be made by participants of the primary wood market in response to the threat of serious consequences of the crisis. In order to identify strategic options reflecting the degree of implementation of the objective function, 9 professional experts, selected from the whole group invited to the study, were invited to their pre-selection, three representatives of each of the sub-sector groups: foresters, forest service entrepreneurs, representatives of the wood industry. Finally, five anti-crisis strategies of varying nature, from institutional intervention preferences to market orientation, were proposed as possible options to choose from [26, 28]. The following strategies have been identified, while at the same time describing their functional structure in a way understandable to practitioners:

- S1: NEUTRAL strategy, as a model 0, market assuming taking into account the dominant influence of market relations on the situation of participants and actors; it was described as follows: "the market will do its own, who survives the crisis, we will cooperate with it";

- S2: EXTENSIVE strategy, as model 1, resource, assuming stimulation of development and possible support for economic activity, based on resources, own or borrowed; it is described as follows: we will grant a resource "loan" to our partners, we will make available resources and raw materials, materials, semi-finished products, we will extend payment deadlines, especially in a situation when we do not bear other costs ourselves than only expense fixed connected with administration and maintenance of resources ";

- S3: INTENSIVE strategy, as a model 3, effective, assuming the separation from the business profile of the entity and stimulation of income activities, and the elimination of unprofitable; it is described as follows: "We optimize and conduct only those lines of business that are active and profitable, while the others are frozen or eliminated, allowing for possible retooling, as well as changing the business profile, provided that we remain in the industry, and in extreme cases we show readiness for solutions marginal, up to and including exit from the industry";

- S4: DIRECT INVESTMENT strategy, as a model 4, investment strategy, which is described as follows: "an industry partner with strong resources takes over or capital entry into a weaker entity, the investment is permanent or temporary, and after entering, and in the extreme case after the acquisition, implements the strategy intense";

- S5: Strategy for COOPERATION NETWORKS, as model 5, also called coopetitive, sharing and relationship, which is described as follows: "existing industry partners of varying sizes and potential, create cooperation networks, initiate resource clusters, mutually sharing those 
resources that are necessary for business maintenance and development; they do not interfere in the partners' property relations, unless they result from the good will of the parties; on a network basis, they can then implement elements of an intensive and / or extensive strategy.

Similarly, from the group of pre-identified economic, social and environmental factors, based on the current state of the art and own research, key factors were selected, which, according to experts, are of fundamental importance for the possible selection of anti-crisis strategy [26, 28]. Finally, 8 factors were selected, giving them the rank of decision optimization criteria:

- F1: enterprise location factor, as criterion 1, describing territorial location, regional dependencies, etc.;

- F2: enterprise size factor, as criterion 2, indicating whether the decision maker is a micro, small and medium or large enterprise;

- F3: factor of the enterprise profile, as criterion 3, describing the leading type of business, as well as the business model and market, supply orientation of the given enterprise;

- F4: factor of cooperation history in the supply chain, as criterion 4, describing economic relations between market participants, in particular in the chain: suppliers - services - processing, emphasizing that it is of key importance in the current purchasing system of wood raw material in Poland;

- F5: the ability to change factor, as criterion 5, characterizing the flexibility of the company's profile, its production or service offer and the degree of its ability to quickly modify or even transform it;

- F6: investment potential factor, as criterion 6, informing about the entity's ability to implement new investments, as well as the creation and implementation of technological innovations;

- F7: financial result factor, as criterion 7, characterizing the entity's current financial position, including financial result, financial liquidity, credit standing and possessed capital resources;

- F8: the factor of sales market diversification, as criterion 8, characterizing the commercial competitive position and demand orientation of the enterprise, the portfolio of key clients, longterm domestic and international trade agreements.

It is worth noting that as a result of the discussion of a team of experts, positive criteria were selected for the research, because the desired solution is a positive strategy - continuation and development of economic activity in the conditions of the economic crisis caused by the impact of a pandemic on the industry market $[59,60,61]$. Next, selected decision options (S1, S2, S3, S4, S5) and decision optimization factors / criteria (F1, F2, F3, F4, F5, F6, F7, F8) were coded to enter them into the working database, enabling execution calculations, normalization, optimization, and then verification and final analysis.

\subsubsection{Research Step 3}

Research Step 3, i.e. the assessment of criteria, which consists in verifying the strength of the impact of selected factors (these are the criteria), in conjunction with decision options.

Depending on the adopted assumptions, the assessed criteria are evaluated by pairwise comparisons by respondents or invited, deliberately selected experts (representing decision-makers). They compare in pairs the proposed decision options in relation to the criteria (factors), and at the same time the criteria in relation to the overarching goal. The comparison always consists of a subjective decision which of the factors (criteria) and to what extent is more important (stronger) than the other in the opinion of the expert.

Relations between particular elements are usually determined by a 9-degree scale of Saaty [43]. Similar proportionality was also used in the conducted research, choosing between: equal significance (measure 1), small advantage (measure 2), strong advantage (measure 5), very strong advantage (measure 7), and absolute advantage (measure 9). Appropriate measures: 2, 4, 6, 8 - 
showed intermediate values [44]. On the other hand, marks about opposite relations were marked as inverts of integers. This stage was finalized by creating a result matrix.

\subsubsection{Research Step 4}

Research Step 4, i.e. determining preferences, consisting in identifying and determining mutual preferences (weights) related to selected factors (criteria) and decision variants (options).

After building the results matrix, weights were calculated for individual criteria. The normalized rows of the result matrix were added by calculating the matrix's vector. The inconsistency coefficient was also taken into account, while the coefficient of consistency and random index were taken into account. This operation verifies the logical value of the results obtained, enabling the elimination of inconsistent responses and outliers [62].

As a result, the relative preference scale was determined for individual data included in the study. In the process of comparing elements, the aforementioned 9-degree scale of relative preference of Saaty was used [44]. The following elements of the scale were distinguished: 5 basic stages (to which particular attention was paid) and, additionally, 4 intermediate stages (in the work the scale was simplified, bypassing these stages in the study). In the basic scale, 5 degrees of preference $(\mathrm{P})$ were distinguished:

- P1: Equivalence, as a grade 1, meaning no preference for compared objects;

- P2: Weak preference, as grade 2, indicating that the first element is weakly preferred to the second, or vice versa;

- P3: A significant preference, as a grade 3, that the first element is significantly preferred to the second, or vice versa;

- P4: A clear preference, as grade 4, indicating that the first element is clearly preferred over the second, or vice versa;

- P5: Absolute preference, as a grade 5, indicating that the first element is absolutely preferred over the second, or vice versa.

\subsubsection{Research Step 5}

Research Step 5, i.e. analysis of the results, finalizing the process, and consisting in choosing the best variant (decision option) that would correspond to the achievement of the overarching goal.

At this stage, an algorithm adapted to the spreadsheet can be used, based on the mathematical assumptions of the AHP method, by normalizing the data and prioritizing decision options (for this purpose, of course, you can use utility or dedicated software (it can be both a spreadsheet, e.g. MS Excel, and professional tools, such as the R program, and "Super Decisions" or "Expert Choice" applications) [41, 44].

\subsection{Selection of Evaluation Criteria in the Designed Research Model}

As it has already been mentioned, based on the deliberately selected key criteria and the diverse, leading strategies corresponding to these criteria, potential decisions of market participants were identified using the tools proposed by the diagnostic survey method. The collected opinions of market actors, coded within the range of selectable decisions, were then verified using the method of multi-criteria hierarchical analysis (AHP), also referring to the general rules for making economic decisions $[44,53,59]$.

The research process is illustrated in the form of a 3-level relationship diagram combining selected factors (F1 ... F8) as decision optimization criteria and anti-crisis strategies (S1 ... S5) as decision options. Therefore, the research was simplified and optimized in the next step (see Figure3). 


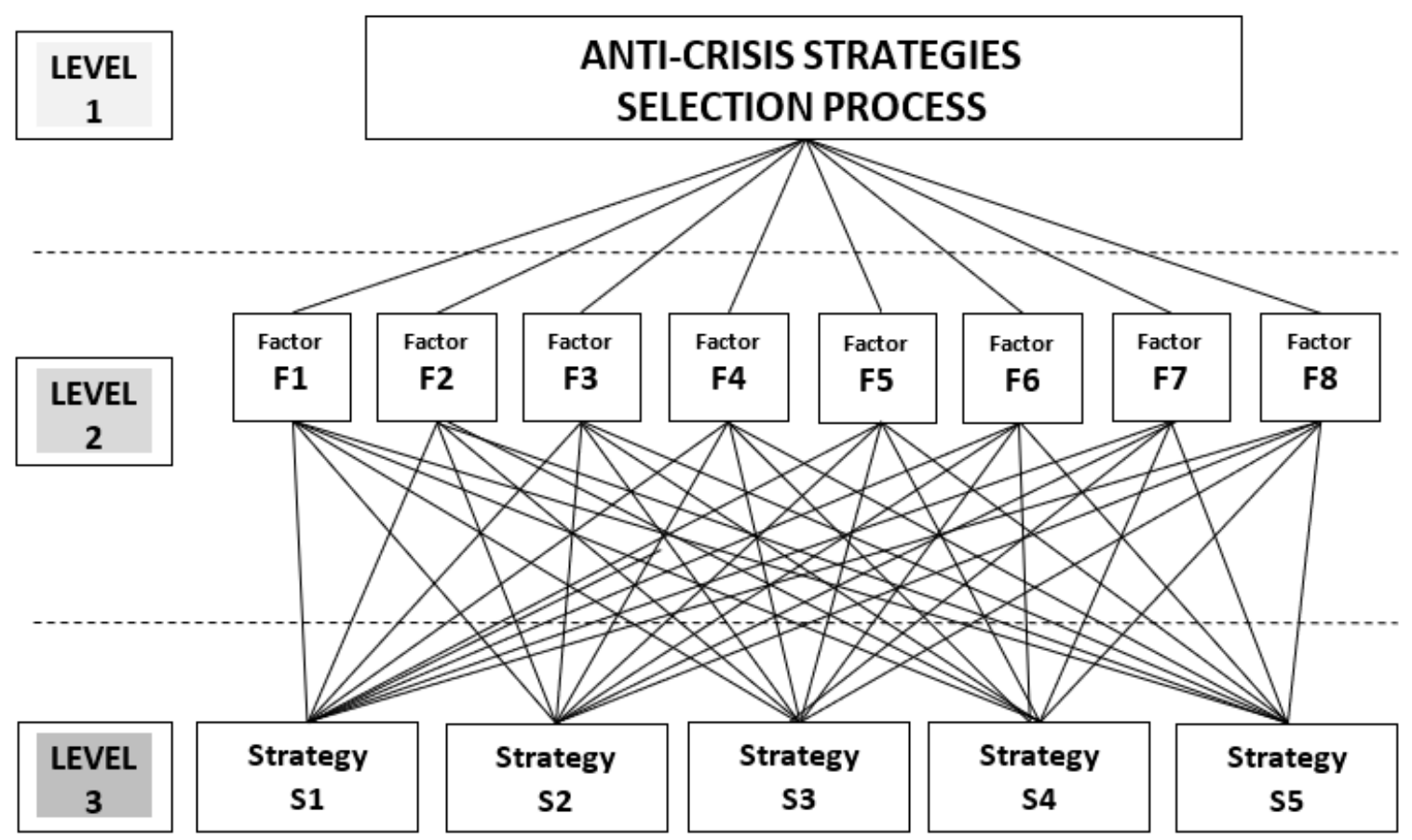

Figure 3. Visualization of the author's scenario of the anti-crisis strategies selection process - according to the AHP method - research levels.

Source: Own study.

Legend: [for level 2] List of factors: F1-location of the enterprise; F2-size of the enterprise; F3-company profile; F4-history of cooperation in the supply chain; F5-ability to change; F6-investment potential; F7-financial result; F8-diversification of the sales market (competitive position); [for level 3] List of anti-crisis strategies: S1-NEUTRAL strategy, market; S2-EXTRENSIVE, resource strategy; S3INTENSIVE, effective strategy; S4-DIRECT INVESTMENT strategy; S5-strategy COOPERATION NETWORKS.

\subsection{Identification of the Impact Strength of the Preferred Option (decision) in the Research Model}

In the next step of the designed scenario, an attempt was made to identify a measure of the ability to implement the optimal decision option, i.e. in the examined case, to effectively take the optimal strategy indicated by the respondents. Using the basic measures of descriptive statistics, classes were determined that corresponded to the measures (strength of influence) of the ability to choose the preferred strategy.

The preferred strategy plays the role of a synthetic variable in this approach. One way to divide the analyzed objects into classes is to use the arithmetic mean and the standard deviation of the synthetic feature $[63,64,65]$. This allows us to distinguish 4 classes (C1 ... C4):

- $\quad$ C1: high development level: $\mathrm{S}_{\mathrm{i}} \geq \overline{\mathrm{S}}+\mathrm{SD}$.

- $\quad$ C2: upper-medium development level: $\overline{\mathrm{S}} \leq \mathrm{S}_{\mathrm{i}}<\overline{\mathrm{S}}+\mathrm{SD}$

- C3: lower-medium development level: $\bar{S}-S D \leq S_{i}<\bar{S}$ and

- C4: low development level: $\mathrm{S}_{\mathrm{i}}<\overline{\mathrm{S}}-\mathrm{SD}$.

Individual symbols mean respectively:

- $S_{i}$ designates the value of the synthetic characteristic for object $\mathrm{i}$; 
- $\overline{\mathrm{S}}$ is the mean value of the synthetic characteristic, and

- $\quad \mathrm{SD}$ is the standard deviation of the synthetic characteristic [65].

The research scenario is finalized by: summary of results, discussion and formal, substantive and descriptive analysis, followed by formulation of conclusions and recommendations.

\section{Presentation and Scientific Discussion of Selected Results}

As a result, based on the collected questionnaires, after rejecting the surveys (interview reports) found to be incorrect, 103 sets of responses were compiled in a uniform result sheet. The structure of the answers obtained was considered symmetrical, as 17 sets (3 questionnaires) from the territory of each of the 17 Regional Directorates of State Forests in Poland were accepted for analysis. In addition, each of the seventeen sets was adopted in the form of 3 separate surveys, representing in all forfeiture of each of the representatives of one of the key subsectors in the forest-wood value chain on the primary wood market: foresters, forestry service entrepreneurs, representatives of woodworking plants. Primary data material collected from the indicated sources was considered valuable. Of course, a question may appear here and immediately afterwards a complaint about the problem of sample representativeness. This allegation could be considered justified if the study were of a statistical nature. Meanwhile, in the process of hierarchical analysis, searching for the optimal decision, you can give the study an expert character, which was done in the presented case. Moreover, even if it were considered to be possible to conduct a statistical study, it would be very difficult to obtain possible results with a relatively high substantive value. In studies on a large scale (number) of respondents, it is usually not possible to conduct in-depth interviews combined with a detailed presentation of the assumptions and research scenario. Therefore, respondents treat surveys spontaneously, with a high degree of randomness. Such studies are usually burdened with relatively large errors. In turn, another threat to research objectivity is conducting official status surveys, surveying the formal representatives of specific institutions and management boards of enterprises, essentially eliminating the factor of anonymity.

The scenario proposed in this paper tried to avoid these weaknesses by seeking a certain aggregation of expert knowledge in anonymous statements of real participants of the primary wood market, actually engaged in economic relations, invited to research. The respondents were given the status of experts in the study. The logical coherence of the statements was also verified by the tools proposed by the AHP method [48, 56, 65]. A high coherence rate was obtained, and hence at least the potential reliability of the results. Although the research sample appears to be modest in numbers, the expert status (on a nationwide scale of over 100) and the polarization of opinions of the three subsectors of the primary wood market constitute, even indirectly, the value and credibility of the final results. In addition, due to the special nature of the circumstances in which the research was conducted, i.e. in a state of real epidemic threat, they were given the rank of pilot studies in the scale obtained, which can or should be continued [61, 66, 67]. With such conviction, the presentation of selected research results began, because, despite the seemingly small research sample, the number of possible shots is very large. For these reasons, only the most important from the point of view of achieving the purpose of the work were selected.

\subsection{Identification of the strength of preferences for proposed anti-crisis strategies by market participants}

The basic question posed at work was the search for an optimal strategy for all entities participating in the primary wood market in Poland, represented by forestry, forest services companies and the wood industry [68,69]. Table 1 summarizes the synthetic distribution of preference strength that was noted in the process of choosing the anti-crisis strategy. These measures, expressed as a percentage, reflect the decisions taken by representatives of various segments of the market under investigation. The results also illustrate the diversity of aggregate decision options that representatives of each of the three subsectors indicated for each of the five strategies proposed. 
Table 1. Differentiation of the preference strength for the selection of the optimal anti-crisis strategy by forestry representatives, forest-services entrepreneurs and the wood industry in an aggregate system.

\begin{tabular}{|c|c|c|c|c|c|c|c|}
\hline \multirow{2}{*}{ No. } & \multirow{2}{*}{$\begin{array}{c}\text { Wood market } \\
\text { participants }\end{array}$} & \multicolumn{5}{|c|}{$\begin{array}{c}\text { Strength of preference for anti-crisis strategies } \\
\text { (according to decision options, aggregated results in\%) }\end{array}$} \\
\cline { 3 - 8 } & $\begin{array}{r}\text { Strategy } \\
\text { S1 }\end{array}$ & $\begin{array}{c}\text { Strategy } \\
\text { S2 }\end{array}$ & $\begin{array}{c}\text { Strategy } \\
\text { S3 }\end{array}$ & $\begin{array}{c}\text { Strategy } \\
\text { S4 }\end{array}$ & $\begin{array}{c}\text { Strategy } \\
\text { S5 }\end{array}$ & Checksum \\
\hline 1. & $\begin{array}{c}\text { Foresters } \\
\text { (State Forests) }\end{array}$ & 11,47 & 16,00 & 16,14 & 19,90 & 36,49 & 100,00 \\
\hline 2. & $\begin{array}{c}\text { Enterpreneuers } \\
\text { of wood industry }\end{array}$ & 9,68 & 18,92 & 16,50 & 24,75 & 30,14 & 100,00 \\
\hline 3. & $\begin{array}{c}\text { Enterpreneuers } \\
\text { of forest-services }\end{array}$ & 12,83 & 12,81 & 16,17 & 14,98 & 43,20 & 100,00 \\
\hline 4. & $\begin{array}{c}\text { All } \\
\text { (aggregation) }\end{array}$ & 11,93 & 16,28 & 15,71 & 19,98 & $\mathbf{3 6 , 1 0}$ & 100,00 \\
\hline
\end{tabular}

Source: Own study based on pilot studies.

Legend: S1-NEUTRAL strategy, market; S2-EXTRENSIVE, resource strategy; S3-INTENSIVE, effective strategy; S4-DIRECT INVESTMENT strategy, investment; S5-strategy COOPERATION NETWORKS, coopetitive.

It is worth noting that all participants of the market studied agreed on the cooperation network strategy, designated S5, as preferred and dominant. This strategy has obtained a synthetic, aggregated preference strength of over 36 percentage points. To the greatest extent, preferences for S5 were indicated by forest-services entrepreneurs. In principle, this compliance also concerned the indication of the S4 investment strategy in second place, although in the forestry service group, priority would be given to the intensive S3 strategy. The least preferred strategy turned out to be the neutral, market strategy S1, for which the synthetic strength of preference was determined at the level of almost 12 percentage points. In addition, an interesting observation is the level of preference close to balance for the choice of S4 investment strategy and S3 efficiency strategy, although with an indication of $\mathrm{S} 4$ by representatives of the wood industry.

\subsection{Priority and hierarchy of choice of anti-crisis strategy}

Analysis of the preference vector in the process of identifying the optimal strategic decision has allowed the indication of priority ranking. This ranking turned out to be relatively orderly, again dominating, indicating priority for the S5 cooperation network strategy, preferred as the most optimal by over 82 percent of respondents (invited experts). This choice, if it were to be the only one, and seen from the perspective of individual decisions, dominated the other options. The S4 strategy proposed as the second in the order gained, as a possible preferred option, only 13 percent of responses. The S3 strategy came next, while the next in the S2 and S1 rankings were completely unacceptable as the preferred strategies. 
Table 2. Preference vector, i.e. ranking of the order of selection of individual strategies and corresponding preference measures of this choice for each of the five proposed anti-crisis strategies.

\begin{tabular}{|c|c|c|c|c|c|c|c|}
\hline \multirow[t]{2}{*}{ No. } & \multirow{2}{*}{$\begin{array}{c}\text { Ranking structure } \\
\text { of indications } \\
\text { (preference vector), } \\
\text { i.e. the order of selection }\end{array}$} & \multicolumn{6}{|c|}{$\begin{array}{l}\text { Preferences in the priority of choosing } \\
\text { anti-crisis strategies } \\
\text { [(S1 ... S5) preference strength in } \%]\end{array}$} \\
\hline & & $\begin{array}{l}\text { Strategy } \\
\text { S1 }\end{array}$ & $\begin{array}{l}\text { Strategy } \\
\text { S2 }\end{array}$ & $\begin{array}{l}\text { Strategy } \\
\text { S3 }\end{array}$ & $\begin{array}{l}\text { Strategy } \\
\text { S4 }\end{array}$ & $\begin{array}{l}\text { Strategy } \\
\text { S5 }\end{array}$ & Checksum \\
\hline 1. & First choice & 0,00 & 0,00 & 4,58 & 13,07 & 82,35 & 100,00 \\
\hline 2. & Second choice & 10,46 & 7,19 & 26,80 & 45,10 & 10,46 & 100,00 \\
\hline 3. & Third choice & 13,07 & 33,33 & 30,72 & 15,69 & 7,19 & 100,00 \\
\hline 4. & Fourth choice & 11,11 & 43,79 & 27,45 & 17,65 & 0,00 & 100,00 \\
\hline 5. & Fifth choice & 65,36 & 15,69 & 10,46 & 8,50 & 0,00 & 100,00 \\
\hline & Checksum & 100,00 & 100,00 & 100,00 & 100,00 & 100,00 & \\
\hline
\end{tabular}

Source: Own study based on pilot studies.

Legend: S1-NEUTRAL strategy, market; S2-EXTRENSIVE, resource strategy; S3-INTENSIVE, effective strategy; S4-DIRECT INVESTMENT strategy, investment; S5-strategy COOPERATION NETWORKS, coopetitive.

Based on the results obtained, the preference vector analysis not only indicates the dominant strategy. The preference for the priority of cooperation networks also indicates the expected tendency that market participants are ready to adopt in order to minimize the possible effects of the economic crisis.

\subsection{Preferences for impact factors - criteria for the selection of anti-crisis strategy by market participants}

By analyzing the distribution of preference strength for impact factors, which are also the criteria for selecting the optimal anti-crisis strategy, he identified the dominant criteria used by representatives of various segments of the primary wood market in Poland, indicating the strategy that interests them. It turned out that from the perspective of each of the subsectors, as well as in the aggregate system, the dominant factor is F4. This factor reflects the history of cooperation in the supply chain: forest - forest services - wood industry. With the greatest strength, although very similar to the decisions of other entities, it was indicated by the wood industry enterprises.

Experts also pointed to the importance of F6 and F7 factors in the process of making strategic decisions in the face of the threat of crisis. All market participants agreed on the importance of investment potential (F6) in the decision optimization process, and sometimes on the financial result. Foresters emphasized the importance of this parameter in a special degree (over 20 percentage points of registered indications). At the same time, a marginal influence of F1, F2 and F3 factors describing the company's basic resource parameters, its location, size and profile was observed. 
Table 3. Differentiation of preference strength in the selection of criteria / factors [F1 ... F8] optimization of strategic decisions for representatives of individual subsectors of the primary wood market in Poland.

\begin{tabular}{|c|c|c|c|c|c|c|c|c|c|c|}
\hline \multirow[t]{2}{*}{ No. } & \multirow[t]{2}{*}{$\begin{array}{l}\text { Wood market } \\
\text { participants }\end{array}$} & \multicolumn{9}{|c|}{$\begin{array}{l}\text { Preferences in the selection of criteria / factors } \\
\text { for optimization of strategic decisions } \\
{[(\mathrm{F} 1 \ldots \mathrm{F} 8) \text { for the subsector in the industry in } \%]}\end{array}$} \\
\hline & & $\mathrm{F} 1$ & F2 & F3 & F4 & F5 & F6 & F7 & F8 & Checksum \\
\hline 1. & $\begin{array}{c}\text { Foresters } \\
\text { (State Forests) }\end{array}$ & 2,73 & 6,60 & 3,58 & 32,25 & 9,04 & 19,50 & 20,03 & 6,27 & 100,00 \\
\hline 2. & $\begin{array}{l}\text { Enterpreneuers } \\
\text { of wood industry }\end{array}$ & 2,12 & 2,67 & 3,84 & 33,68 & 12,94 & 19,29 & 13,23 & 12,24 & 100,00 \\
\hline 3. & $\begin{array}{l}\text { Enterpreneuers } \\
\text { of forest-services }\end{array}$ & 3,80 & 3,64 & 5,16 & 33,56 & 14,12 & 16,40 & 16,96 & 6,36 & 100,00 \\
\hline 4. & $\begin{array}{c}\text { All } \\
\text { (aggregated) }\end{array}$ & 2,87 & 4,33 & 4,17 & 33,15 & 11,99 & 18,43 & 16,76 & 8,30 & 100,00 \\
\hline
\end{tabular}

Source: Own study based on pilot studies.

Legend: F1-location of the enterprise; F2-size of the enterprise; F3-company profile; F4-history of cooperation in the supply chain; F5-ability to change; F6-investment potential; F7-financial result; F8diversification of the sales market (competitive position).

5.4. Differentiation of the importance of impact factors - criteria for the selection of anti-crisis strategy in a spatial arrangement

Then, analyzing the differentiation of the impact strength for individual factors - criteria for the selection of anti-crisis strategy in the spatial arrangement, defined territorially by the borders of the Regional Directorates of State Forests in Poland, analogous observations were obtained that were obtained for primary wood market entities [70].

It turned out that from the perspective of each of the forest regions (regional directorates) as well as in the national perspective, the dominant factor is the history of cooperation in the supply chain: forest - forest services - wood industry (i.e. F4). His influence was observed with the greatest strength within the Gdansk, Cracow and Zielona Góra directorates. In addition, also in analogy to the subsector system, the influence of F6 and F7 factors was identified.

Particular attention was paid to the impact of investment potential (F6) in the area of the Katowice, Krosno and Warsaw Directorates, and the financial result (F7) mainly in Wielkopolska (Poznań and Szczecin Directorates) and in Warmia and Mazury (Olsztyn Directorate). Other factors played a marginal role in the decision-making process. Only in the Directorate of Lublin attention was paid to the impact of the sales market diversification factor (F8). 
Table 4. Variation in the impact strength of individual factors [F1 ... F8] / criteria for optimizing strategic decisions in a regional system, for 17 areas of the Regional Directorates of State Forests in Poland.

\begin{tabular}{|c|c|c|c|c|c|c|c|c|c|c|}
\hline \multirow[t]{2}{*}{ No. } & \multirow{2}{*}{$\begin{array}{c}\text { Regional } \\
\text { Directorates } \\
\text { of State Forests } \\
\text { in Poland }\end{array}$} & \multicolumn{9}{|c|}{$\begin{array}{l}\text { Diversity of preferences strength selection criteria / factors } \\
{[\mathrm{F} 1 \ldots \mathrm{F} 8] \text { optimization of strategic decisions in the spatial system }}\end{array}$} \\
\hline & & F1 & $\mathrm{F} 2$ & F3 & F4 & F5 & F6 & F7 & F8 & Checksum \\
\hline 1 & Białystok & 3,01 & 3,38 & 4,58 & 34,25 & 12,77 & 21,08 & 12,94 & 7,99 & 100,00 \\
\hline 2 & Gdańsk & 2,84 & 3,62 & 4,25 & 36,49 & 10,24 & 19,81 & 14,49 & 8,27 & 100,00 \\
\hline 3 & Katowice & 2,81 & 4,68 & 4,44 & 32,38 & 11,55 & 23,37 & 12,17 & 8,61 & 100,00 \\
\hline 4 & Kraków & 2,94 & 4,07 & 4,30 & 36,20 & 10,94 & 16,09 & 17,65 & 7,81 & 100,00 \\
\hline 5 & Krosno & 3,62 & 4,28 & 4,64 & 28,59 & 13,59 & 25,65 & 10,34 & 9,29 & 100,00 \\
\hline 6 & Lublin & 3,08 & 3,47 & 4,64 & 30,31 & 15,01 & 21,95 & 11,29 & 10,25 & 100,00 \\
\hline 7 & Łódź & 2,84 & 4,72 & 3,99 & 33,72 & 11,71 & 18,31 & 18,14 & 6,57 & 100,00 \\
\hline 8 & Olsztyn & 2,31 & 4,89 & 3,91 & 33,04 & 10,75 & 12,36 & 25,09 & 7,66 & 100,00 \\
\hline 9 & Piła & 2,78 & 5,45 & 4,13 & 32,87 & 11,88 & 18,26 & 17,20 & 7,43 & 100,00 \\
\hline 10 & Poznań & 2,18 & 6,29 & 3,28 & 32,30 & 10,82 & 11,27 & 26,05 & 7,80 & 100,00 \\
\hline 11 & Radom & 3,18 & 3,33 & 4,10 & 32,18 & 13,53 & 16,64 & 17,45 & 9,60 & 100,00 \\
\hline 12 & Szczecin & 3,99 & 3,59 & 3,93 & 34,09 & 13,59 & 18,37 & 14,48 & 7,96 & 100,00 \\
\hline 13 & Szczecinek & 2,73 & 4,47 & 3,63 & 33,96 & 11,56 & 12,35 & 23,34 & 7,96 & 100,00 \\
\hline 14 & Toruń & 2,62 & 4,51 & 4,11 & 32,54 & 10,68 & 18,92 & 18,79 & 7,84 & 100,00 \\
\hline 15 & Warszawa & 3,00 & 3,61 & 4,99 & 32,06 & 12,96 & 22,29 & 12,45 & 8,64 & 100,00 \\
\hline 16 & Wrocław & 2,57 & 5,25 & 3,90 & 32,23 & 9,86 & 19,69 & 18,60 & 7,90 & 100,00 \\
\hline 17 & Zielona Góra & 2,28 & 3,96 & 4,14 & 36,30 & 12,19 & 16,98 & 14,63 & 9,51 & 100,00 \\
\hline & Checksum & 100,00 & 100,00 & 100,00 & 100,00 & 100,00 & 100,00 & 100,00 & 100,00 & \\
\hline
\end{tabular}

Source: Own study based on pilot studies.

Legend: F1-location of the enterprise; F2-size of the enterprise; F3-company profile; F4-history of cooperation in the supply chain; F5-ability to change; F6-investment potential; F7-financial result; F8diversification of the sales market (competitive position).

5.5. Regional diversity of strength / ability to create cooperation networks by the surveyed participants of the wood market

Because as the dominant conclusion from the analysis so far, the decisive tendency of the participants of the primary wood market to choose cooperation strategy (S5) was identified, based on the creation of cooperation and coopetition networks, it was considered appropriate to examine the diversity of this tendency in the spatial and regional system. For this purpose, the linear ordering method was used to analyze the collected data. Therefore, the respective values of the arithmetic mean and standard deviation were determined.

Then, for each of the regions (i.e. territories designated by the Regional Directorates of State Forests), ranking positions were verified, determining 4 classes. In each class, regions were grouped for which the decisions taken by the experts corresponded to the strength of the dominant strategy, analogous to the degree/level of hierarchy. The obtained results are illustrated in Figure 4. 


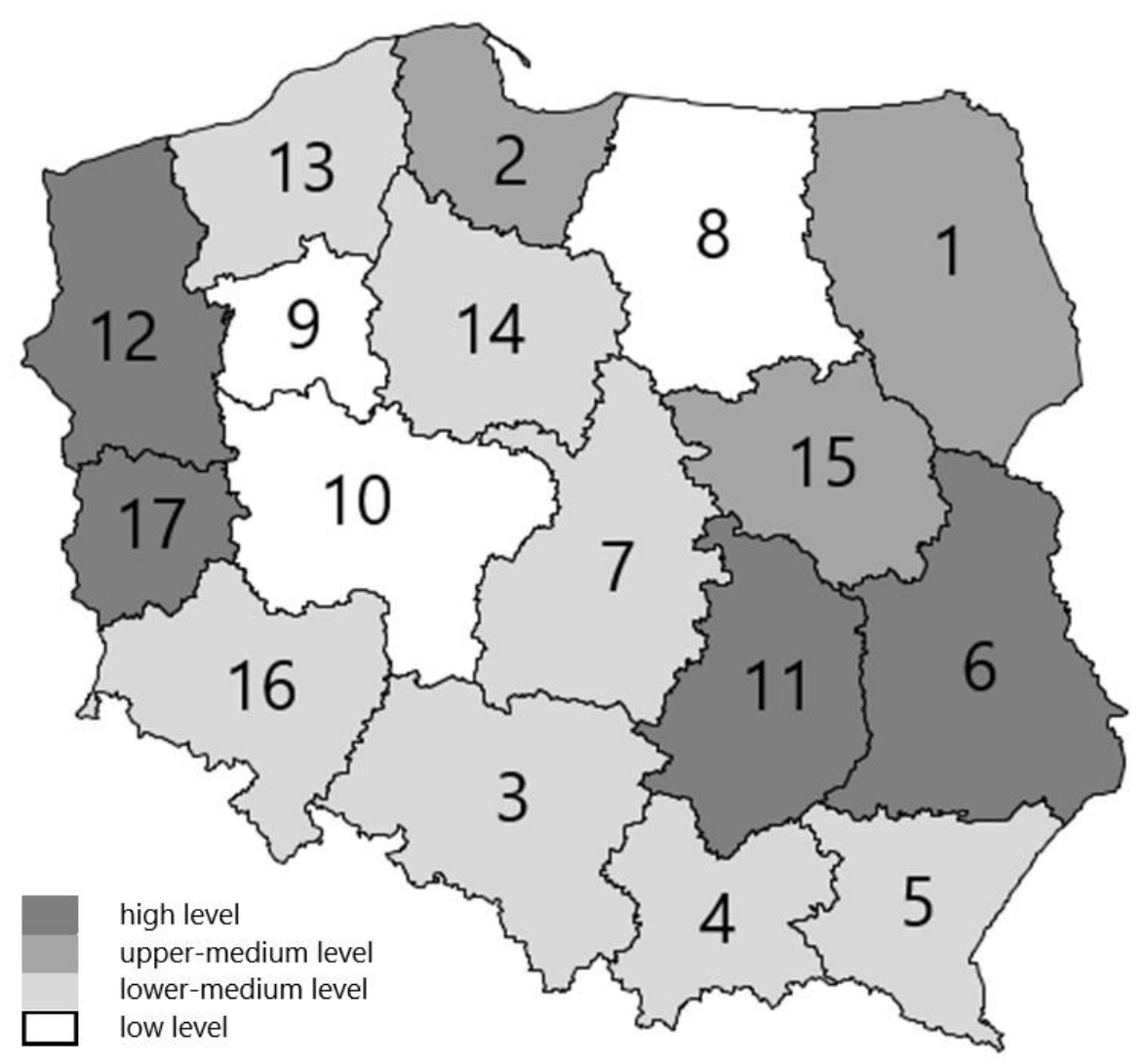

Figure 4. Differentiation of the ability to effectively choose the preferred anti-crisis strategy (according to the measure of preference strength) in the regional system (for territories designated by the area of each of the 17 Regional Directorates of State Forests in Poland), in 4 classes (C1 ... C4), reflecting the level of preference.

Source: Own study based on pilot studies.

Legend: * Classes (preference levels): C1-high level; C2-upper-medium level; C3-lower-medium level, C4-low level; ${ }^{* *}$ Regional Directorates of State Forests in Poland (on the map numbered from 1 to 17 in alphabetical order and identified by city name - headquarters): 1-Białystok; 2-Gdańsk; 3 Katowice; 4-Kraków; 5-Krosno; 6-Lublin; 7-Łódź, 8-Olsztyn, 9-Piła, 10-Poznań, 11-Radom, 12-Szczecin; 13Szczecinek, 14-Toruń, 15-Warsaw, 16-Wrocław, 17-Zielona Góra.

The calculated values of the arithmetic mean (36.49\%) and standard deviation (2.86\%) were grouped, assigning classes corresponding to the measures of the ability to create a cooperation network in each of the areas designated by individual Regional Directorates of State Forests. Each of the four classes corresponds to the category of potential cooperation strength of market participants in a given area. It is worth noting that the designated compartments are not symmetrical. Percentage limits were as follows:

- Class 1: high power of cooperation level: $40,04 \% \geq S_{i}>39,15 \%$.

- Class 2: upper-medium power of cooperation level: $39,15 \% \geq S_{i}>36,49 \%$.

- Class 3: lower-medium power of cooperation level: $36,49 \% \geq S_{i}>33,83 \%$.

- Class 4: low power of cooperation level: $33,83 \% \geq S_{i}>31,1 \%$.

It was noticed that in the dominant group, showing the highest level of preferences for the strategy based on networking, it occurs in areas characterized by a relatively high degree of forest 
cover. This applies above all to the territory of the Szczecin and Zielona Góra Directorates (area of western and northern Poland), but also of the Radom and Lublin Directorates (eastern Poland). On the other hand, three regions were identified at the medium-high level: the territory of the Białystok, Gdańsk and Warsaw Directorates. It seems that just for these areas, the promotion of network cooperation strategies may turn out to be particularly attractive and effective at the same time, due to the readiness to implement it by all market participants. At the same time, as many as seven forest regions, mainly from southern and central Poland, were classified at medium low. However, this does not mean a lack of interest in implementing coopetition strategies in the wood-based sector in these areas, and only this result indicates a weaker propensity to implement this strategy. Finally, it was noted that the regions least interested in the implementation of network cooperation strategies could be identified, although indicating this strategy as the preferred one during the crisis [71]. These regions include the territories of the Poznań, Piła and Olsztyn Directorates.

In conclusion, it is worth noting that the additional analysis carried out by the method of linear ordering also reveals some behavioral aspects of decisions made by wood market participants. Conducting in-depth research in this area can be used both during the crisis and in the future, as a support for programming various regional policy instruments in the forestry and wood-based sector $[72,73]$, adequate for the specificity of these regions, identified as functional forest-wooded areas.

\section{Conclusions and Recommendations}

In the conducted research, the scope and results of which are documented in this paper, the optimal strategy for action was sought, adequate to the current economic situation, which would help participants in the forest and wood-based sector to reduce the impact of negative factors of the crisis resulting from a global pandemic. Symptoms of the crisis have already emerged, and only short-term, ad hoc measures have been implemented so far. There is no medium- and long-term vision, no strategy, and no industry policy directions for forestry. The questions posed at work are actually and not just hypothetically sought for answers. Therefore, referring to the conducted pilot studies, after analyzing and discussing the results, the following conclusions and recommendations were formulated:

1) Participants of the researched wood market, aware of the economic threats resulting from restrictions in the functioning of the economy in pandemic conditions, confirmed, through readiness to participate of their representatives in expert research, the willingness to jointly search for specific solutions and indicate adequate action strategies.

2) It turned out, despite initial concerns about the lack of a possible consensus of entities forming the first link in the forest-wood value chain, in the system: traditional forestry - forest services - wood industry, obtaining the answer to the question about the optimal anti-crisis strategy for the entire sector is possible.

3) In addition, it was found that the process of identifying the optimal decision for a large group of market participants successfully supports the application, after adaptation, of selected hierarchical analysis methods. This was shown on the example of the AHP method, based on the targeted selection of study participants profiled for expert analysis. The analyzes carried out with this relatively simple method allowed to obtain satisfactory results, if referring to the requirements of the pilot study.

4) It was found that among the five anti-crisis strategies proposed, with a varied profile, from market-oriented to institutional orientation, the respondents clearly defined their preferences, pointing to one dominant strategy. It was considered that in order to secure the interests of various participants of the primary wood market in Poland, the best solution would be to implement an anticrisis strategy based on the development of a cooperation network integrating entities in the sector. By using the coopetition mechanism, it is possible in this way, by making available resources mutually available, to secure, maintain and then develop the ventures carried out.

5) In addition, it was noted that the selection of the next hierarchical investment strategy (based on development potential), as well as an intensive strategy, focusing on supporting effective business components, can complement the leading strategy of "networking" relationships in the industry. 
6) This direction was also confirmed by the preferences of the selection of key factors for strategic decision optimization, among which priority was given to the history of cooperation in the supply chain and investment potential. As part of in-depth interviews, it was pointed out that the strength of this potential was determined not only by traditional resources, but also by innovation and coopetition.

7) It should be noted, therefore, that the hypothesis set out at the beginning, which assumed that it is possible to choose the optimal anti-crisis strategy adequate to the identified market situation of entities participating in forestry and the wood-based sector, has been positively verified.

8) It was further confirmed that by using a method that is as simple as possible, understood by decision-makers (on the example of AHP), it is possible to at least partially reduce the level of uncertainty in the decision-making process, especially when it comes to the need to urgently indicate the optimal strategic decision taken in the face of a real threat crisis.

The advantages of the method used in the work include: flexibility, simplicity of use, the ability to compare both qualitative and quantitative factors, verification of logical correctness. Many decision-making processes in forestry and the wood-based sector can successfully refer to the assumptions of the Analytic Hierarchy Process (AHP) and Analytic Network Process (ANP) methods. For the usually analyzed subsystems: benefits, costs, opportunities and risks, it is possible to formulate organizational, production, technological and economic criteria for which, in turn, the values of priorities (weights) can be calculated. Thus, it becomes relatively simple and feasible to determine the optimal decision model (strategy), indicating significant benefits and threats.

The obtained results also indicate, on the example of Poland, the need to revise the current development policy in forestry and the wood-based sector. It seems necessary to verify the relationship between market and institutional entities (in Poland, state forest management is a natural monopoly). This applies to both inter-sector and inter-sector links as well as institutional relations. Much clearer, precisely in the conditions of the epidemic crisis, one can also see the specific crisis of the traditional competitive advantage model. A new competitiveness model is emerging. It seems that it can be based on: the ability to plan development in the local and functional (territorial) dimension, on integration and building cooperation in the process of delivering products and services, and finally on striving for the efficiency of ventures and establishing lasting, multidirectional relationships. Such a model may have a structure not so much balanced as an integral one, and forestry and the wood-based sector may be a good example of an integral sector of the economy, aiming at the rational use of resources in the circular economy formula.

Supplementary Materials: All additions are included in the text.

Author Contributions: Conceptualization, L.W., R.C. and W.K.; Data curation, L.W., W.K., E.M., Ł.S. and M.W.; Formal analysis, L.W., R.C., W.K. and M.W.; Funding acquisition, L.W. and E.M.; Investigation, L.W.; Methodology, L.W., J.S. and Ł.S.; Project administration, L.W. and E.M.; Resources, L.W.; Software, L.W. and Ł.S.; Supervision, L.W.; Validation, L.W., R.C. and J.S.; Visualization, Ł.S.; Writing - original draft, L.W. and R.C.; Writing - review and editing, L.W. and R.C.

Funding: This research received no external funding.

Acknowledgments: The authors thank the editors of the Polish professional and scientific journal "The Forestry Review" ("Przeglad Leśniczy") for the inspiration and all the support provided during the preparatory part and implementation of the research. Special thanks are addressed to those Polish foresters, employees of the State Forests and entrepreneurs from the forest services and wood industry who responded to the authors' invitation. Thank you for your kindness, reliability and commitment during the development of research questionnaires and in-depth expert interviews. This gratitude is even greater because all mentioned above devoted their time, regardless of the difficulties arising from epidemic threats and economic problems, and have done their work honorably, not expecting gratification.

Conflicts of Interest: The authors declare no conflict of interest. 


\section{References}

1. Von Carlowitz, H. C. Sylvicultura Oeconomica [Economic Forestry]. Leipzig: Braun. 1713.

2. Von Carlowitz, H. C. Sylvicultura Oeconomica [Economic forest management] oder Hausswirthliche Nachricht und naturmässige Anweisung zur wilden Baumzucht (reprint from 2000 edited by K. Irmer). Technische Universität Bergakademie Freiburg, Freiburg, 2000.

3. Chudobiecki, J.; Wanat, L. Industrial Symbiosis and Green Business Parks in The Wood-Based Sector in Poland. In Wood Processing and Furniture Manufacturing Challenges on the World Market; Chobanova, R., Eds.; WoodEMA: Zagreb, Croatia, 2015; pp. 221-228.

4. Elliott, J. An introduction to sustainable development. Routledge, 2012.

5. Słodowa-Hełpa, M. Rozwój zintegrowany. Warunki, wymiary, wyzwania [Integral Development. Conditions, Scope, Challenges]. CeDeWu, Warszawa, Poland, 2013.

6. Keynes, J.M.; Moggridge, D.E.; Johnson, E.S. The Collected Writings of John Maynard Keynes. Vol. 1. London:, Macmillan, 1971.

7. Davis, J.B., ed. The state of interpretation of Keynes. Vol. 44. Springer Science \& Business Media, 2012.

8. Lawlor, M. The economics of Keynes in historical context: an intellectual history of the general theory. Springer, 2016.

9. Manh, D., Trinh, B. Forestry Sector and Policies on Sustainable Development in Vietnam: Analyze from the Input-Output Model. International Journal of Social and Administrative Sciences. 2019. Vol. 4, No. 2, 253-266. DOI: 10.18488/journal.136.2019.42.253.266 2019.

10. Chen, Y. The Contributions and Deficiencies of Keynesian Economics. In New Economic Engine: Effective Government and Efficient Market (pp. 11-21). Springer, Singapore, 2020.

11. Friedman, M. The Methodology of Positive Economics, Essays in Positive Economics. University of Chicago Press, Chicago, 1953, reprinted by Phoenix Books, Chicago, 1966.

12. Anderson, T.L.; Huggins, L.E.; Friedman, M. The property rights path to sustainable development. Free to Choose, 2003, 57.

13. Hammond, J.D. Theory and measurement: Causality issues in Milton Friedman's monetary economics. Cambridge University Press, 2005.

14. Humphreys, D. Discourse as ideology: Neoliberalism and the limits of international forest policy. Forest policy and economics, 2009, 11 (5-6), 319-325.

15. Samad, A.R.A.; Ashhari, Z.M.; Othman, M.S.H. Sustainable forest management practices and West Malaysian log market. Asian Social Science, 2009, 5(6), P69.

16. Adamowicz, K. Ocena zmian gospodarki leśnej prowadzonej przez Państwowe Gospodarstwo Leśne Lasy Państwowe w handlu drewnem w Polsce. Rozprawy Naukowe. Uniwersytet Przyrodniczy w Poznaniu, 441. Poznań, Poland, 2012.

17. Ratajczak, E. Sektor leśno-drzewny w zielonej gospodarce. Wydawnictwo Instytutu Technologii Drewna, Poznań, Poland, 2013.

18. Szramka, H., Adamowicz, K. Kierunki modyfikacji statusu Lasów Państwowych w Polsce [Trends in modification of the status of the State Forests in Poland]. Sylwan, 2017, 161(05), pp. 355-364

19. Chobanova, R.; Kotseva, M.; Mouchurova, M. From Linear to Circular Economy: The Role OF Forests (Survey of WoodEMA associated publications). In Chobanova R., ed., Digitalisation and Circular Economy: forestry and forestry based industry implications, 11-13.09.2019, Varna, USB \& WoodEMA, i.a., Sofia, Bulgaria, pp. 11-22.

20. Bergen, V.; Löwenstein, W.; Olschewski, R. Forstökonomie: Volkswirtschaftliche Ansätzefür eine Vernünftige Umwelt-und Landnutzung. Vahlen Franz, Munchen, Germany, 2013.

21. GUS Statistical Yearbook of Forestry / Rocznik Statystyczny Leśnictwa. Central Statistical Office. Warszawa, Poland, 2019. Available online: https://stat.gov.pl/obszary-tematyczne/roczniki-statystyczne/rocznikistatystyczne/rocznik-statystyczny-lesnictwa-2019,13,2.html\# (accessed on 21 March 2020).

22. Wanat, L.; Klus, S. Sytuacja konkurencyjna branży i mezoekonomiczne aspekty polityki sektorowej państwa na przykładzie rynku drzewnego w Polsce [The Competitive Situation and Mesoeconomic Aspects of Industrial Policy Based on Example of the Wood Market in Poland]. Rynek - Społeczeństwo Kultura, 2015, No. 1(13), pp. 41-55. Available online: www.kwartalnikrsk.pl/de/assets/rsk1-2015wanat_klus.pdf (accessed on 25 March 2020).

23. Meskin, A.; Borkowski, P. State Forests in the Baltic Sea Region: Where experience meets challenges and future opportunities, In Liuhto, K. (eds.). The forest industry around the Baltic Sea region: Future 
challenges and opportunities, BSR Policy Briefing series, 1/2020, p. 30, Centrum Balticum Foundation. Available online: https://www.centrumbalticum.org/files/4638/BSR_Policy_Briefing_2020.pdf, accessed: 21 April 2020, ISSN: 2342-3153.

24. Gołos, P.; Hilszczański, J. Social and economic importance of the forestry and wood sector in Poland, In Liuhto, K. (eds.). The forest industry around the Baltic Sea region: Future challenges and opportunities, BSR Policy Briefing series, No. 1, 2020, p. 40. Centrum Balticum Foundation. Spatial data based on: Instytut Badawczy Leśnictwa (Forest Research Institute), Sękocin Stary, Poland, ISSN: 2342-3153, https://www.centrumbalticum.org/files/4638/BSR_Policy_Briefing_2020.pdf, accessed: 21 April 2020.

25. Potkański, T.; Wanat, L. Dylematy rozwoju miejskich obszarów funkcjonalnych z perspektywy partnerstw międzysamorządowych. Studia KPZK, 2017, 1, 235-245.

26. Wanat, L.; Potkański, T.; Chudobiecki, J.; Mikołajczak, E.; Mydlarz, K. Intersectoral and Intermunicipal Cooperation as a Tool for Supporting Local Economic Development: Prospects for the Forest and WoodBased Sector in Poland. Forests 2018, 9, 531, https://doi.org/10.3390/f9090531.

27. Kusiak, W.; Mikołajczak, E.; Wanat, L. Institutional and Industrial Symbiosis Case Study of Cooperation for Development in Forestry and Wood-Based Sector. In Glavonic, B., ed., Increasing the Use of Wood in the Global Bio-Economy, 26-28.09.2018, Belgrade, Serbia. WoodEMA i.a., Zagreb, Croatia, 2018, pp.388-388.

28. Wanat, L.; Majchrzak, L.; Mikołajczak, E.; Klus, S. The Symbiosis Prospects for the E-Commerce Business and Wood-Based Sectors - the Case of Poland. In Chobanova R., ed., Digitalisation and Circular Economy: forestry and forestry based industry implications, 11-13.09.2019, Varna, USB \& WoodEMA i.a., Sofia, Bulgaria, 2019, pp. 169-174.

29. Stanley-Smith, J. Europe, Middle East and Africa: EMEA corporations restructure as tax planning enters a new era. International Tax Review, 2018.

30. Weber, A. Alfred Weber's Theory of the Location of Industries. Chicago University of Chicago Press: Chicago, IL, USA, 1909.

31. Jones, C. Spatial economy and the geography of functional economic areas. Environ. Plan. B Urban Anal. City Sci. 2017, 44, pp. 486-503.

32. Fujita, M.; Krugman, P.R. The new economic geography: Past, present and the future. Pap. Reg. Sci. 2004, 83, 139-164.

33. Porter, M.E. Regional Competitiveness in a Global Economy; The Brookings Institution: Washington, DC, USA, 2008.

34. Lessem, R.; Schieffer, A. Integral Economics: Releasing the Economic Genius of Your Society; Routledge: Oxon, UK, 2016.

35. Márquez, M.A.; Lasarte, E.; Lufin, M. The Role of Neighborhood in the Analysis of Spatial Economic Inequality. Soc. Indic. Res. 2017, 1-29.

36. Chobanova R. Innovativeness of a national economy: The case of Bulgaria. Lambert Academic Publishing, Germany, 2011, 361 p.

37. Hogarth, R. M. Judgement and choice: The psychology of decision. No. Sirsi i9780471914792, 1987.

38. Morton, A.; Fasolo, B. Behavioural decision theory for multi-criteria decision analysis: a guided tour, Journal of the Operational Research Society, 2009, 60:2, 268-275, DOI: 10.1057/palgrave.jors.2602550.

39. Jang, I. The Pareto principle and resource egalitarianism. Mathematical Social Sciences, 2017, 85, $23-29$.

40. Saracoglu, B.O. Analytic network process vs. Benjamin Franklin's rule to select private small hydropower plants investments. MedCrave Group LLC, Istanbul, Turkey, 2018. Available online: https://medcraveebooks.com/view/Analytic-network-process-vs-Benjamin-Franklin's-rule-to-selectprivate-small-hydropower-plants-investments.pdf (accessed on 25 March 2020).

41. Asadabadi, M. R.; Chang, E.; Saberi, M. Are MCDM methods useful? A critical review of Analytic Hierarchy Process (AHP) and Analytic Network Process (ANP). Cogent Engineering, 2019, 6(1), 1623153.

42. Saaty, T.L. What is the analytic hierarchy process? In Mathematical models for decision support. Springer, Berlin, Heidelberg, 1988, pp. 109-121.

43. Saaty, T.L. Decision making with the analytic hierarchy process. International Journal of Services Sciences, 2008, 1(1), 83-98.

44. Prusak, A.; Stefanów, P.; Strojny, J.; Garcia-Melon, M. The Influence of the Form of the 9-Point Scale in the AHP Method on the Consistency of Judgments. Modern Management Review, 2016, 21(23 (3)), 97-113.

45. Lima-Junior, F.R.; Carpinetti, L.C.R. Dealing with the problem of null weights and scores in Fuzzy Analytic Hierarchy Process. Soft Computing, 2019, 1-17. 
46. Dos Santos, P.H.; Neves, S.M.; Sant'Anna, D.O.; de Oliveira, C.H., Carvalho, H.D. The analytic hierarchy process supporting decision making for sustainable development: An overview of applications. Journal of Cleaner Production, 2019, 212, 119-138.

47. Wątróbski, J.; Jankowski, J.; Ziemba, P.; Karczmarczyk, A.; Zioło, M. Generalised framework for multicriteria method selection. Omega, 2019, 86, pp. 107-124.

48. Forman, E.H.; Gass, S.I. The analytic hierarchy process-An exposition. Operations Research, 2001, 49(4), 469-486. https://doi.org/10.1287/opre.49.4.469.11231.

49. Kowalczyk, A. M.; Bajerowski, T. Development of the Theory of Six Value Aggregation Paths in Network Modeling for Spatial Analyses. ISPRS International Journal of Geo-Information, 2020, 9(4), 234.

50. Wright, G.; Cairns, G.; O'Brien, F.A.; Goodwin, P. Scenario analysis to support decision making in addressing wicked problems: Pitfalls and potential. European Journal of Operational Research 2019, 278(1), 319.

51. Goodwin, P. Supporting multiattribute decisions in scenario planning using a simple method based on ranks. Futures $\mathcal{E}$ Foresight Science 2019, 1(3-4), e00018.

52. Robinson, K.F.; Fuller, A.K.; Stedman, R.C.; Siemer, W.F.; Decker, D.J. Integration of social and ecological sciences for natural resource decision making: challenges and opportunities. Environmental management 2019, 63(5), 565-573.

53. Mikołajczak, E.; Sarniak, Ł.; Wanat, L. Synthetic measures as a tool for identitying the potential of the woodbased industry selected sectors. In Chobanova, R., ed., Digitalisation and Circular Economy: forestry and forestry based industry implications, 11-13.09.2019, Varna, USB \& WoodEMA, i.a., Sofia, Bulgaria, 2019, pp. 245-250.

54. Pei, A.; Wang, J. Nonlinear analysis of return time series model by oriented percolation dynamic system. In Abstract and Applied Analysis, 2013. Hindawi.

55. Azimifard, A.;Moosavirad, S.H.; Ariafar, S. Selecting sustainable supplier countries for Iran's steel industry at three levels by using AHP and TOPSIS methods. Resources Policy 2018, 57, 30-44.

56. Konstantinos, I.; Georgios, T.; Garyfalos, A. A Decision Support System methodology for selecting wind farm installation locations using AHP and TOPSIS: Case study in Eastern Macedonia and Thrace region, Greece. Energy Policy 2019, 132, 232-246.

57. Mohapatra, P.K. Supplementary Research Methods: DEA, ISM, AHP and Non-Parametric Statistics. In Methodological Issues in Management Research: Advances, Challenges, and the Way Ahead. Emerald Publishing Limited, 2019.

58. Heindl, A.B.; Liefner, I. The Analytic Hierarchy Process as a methodological contribution to improve regional innovation system research: Explored through comparative research in China. Technology in Society 2019, 59, 101197.

59. Wanat, L.; Mikołajczak, E.; Sarniak, Ł.; Czarnecki, R.; Topczewska A. Application of the Analytic Hierarchy Process (AHP) algorithm to optimise business models for the kitchen furniture market. In Jelaĉić, D., ed., Management aspects in forestry and forest based industries, WoodEMA ia., Zagreb, Croatia, 2020 (in print).

60. Šupín, M.; Kaputa, V.; Matová, H. International Forest Products Marketing. Technical University in Zvolen, Faculty of Wood Sciences and Technology, Zvolen, Slovakia, 2015.

61. Šupín, M., The impact of the global recession on wood processing industry and wood products trade and the road to recovery. In Position and role of the forest based sector in the green economy. Proceedings of scientific papers, Zagreb: WoodEMA, 2014, pp. 159-164.

62. Okupniak, M.; Wanat, L.; Mikołajczak, E.; Sarniak, Ł.; Dolacińska-Śróda, A. Selected outlier identification methods in the wood-based sector competitiveness potential research. Intercathedra 2017, (33 (4)), 82-88.

63. Adamus, W.; Wysocki, F. Application of taxonometric and decision-making methods to drafting scenarios of rural area development. ISAHP 2003, Bali, Indonesia, August 7-9, 2003. Available online, isahp.org/2003Proceedings/paper/p07.pdf (accessed on 21 March 2020).

64. Wysocki, F. Metody taksonomiczne w rozpoznawaniu typów ekonomicznych rolnictwa i obszarów wiejskich [Taxonomic methods in recognizing economic types of agriculture and rural areas]. Poznań: Uniwersytet Przyrodniczy w Poznaniu, Poland, 2010.

65. Łuczak, A. Assessing the Strategic Factors and Choosing the Development Scenarios for Local Administrative Units Using AHP. Multiple Criteria Decision Making 2017, 12, 119-133. 
66. Potkány, M.; Škultétyová, M.; Debnár, M. The Potential of Subsidy Schemes to the Support of Wooden Houses Construction in the Context of the green Economy. In Economics, Management and Technology in Enterprises 2019 (EMT 2019). Atlantis Press, 2019.

67. Potkány, M.; Gejdoš, M.; Debnár, M. Sustainable innovation approach for wood quality evaluation in green business. Sustainability 2018, 10(9), 2984.

68. Paluš, H.; Parobek, J.; Vlosky, R.; Motik, D.; Oblak, L.; Jošt, M.; Glavonjić, B.; Dudík, R.; Wanat, L. The status of chain-of-custody certification in the countries of Central and South Europe. Eur. J. Wood Wood Prod. 2018, 76, 699-710.

69. Chudobiecki, J.; Potkański, T.; Wanat, L. Intermunicipal and Inter-sectoral Cooperation as a Tool Supporting Local Economic Development. In Proceedings of the 9th International Scientific Conference on The Path Forward for Wood Products: A Global Perspective, Baton Rouge, LA, USA, 5-8 October 2016; WoodEMA: Zagreb, Croatia, 2016.

70. Nováková, R.; Pauliková, A.; Canet, N. The Process of Indexing Working Comfort Factors in Organizations of Wood Processing Industry. In Chobanova, R., ed., Digitalisation and Circular Economy: forestry and forestry based industry implications, 11-13.09.2019, Varna, USB \& WoodEMA, i.a., Sofia, Bulgaria, 2019, pp. 269-275.

71. Luo, X.; Slotegraaf, R.J.; Pan, X. Cross-functional "coopetition": The simultaneous role of cooperation and competition within firms. J. Mark. 2006, 70, 67-80.

72. Wanat, L.; Lis, W. Promotion of Best Practices - Project Proposal for the Wood Industry in Poland. Intercathedra 2009, 25, pp. 151-155.

Dobšinská, Z.; Živojinović, I.; Nedeljković, J.; Petrović, N.; Jarský, V.; Oliva, J.; Šálka, J.; Sarvašová, Z.; Weiss, G. Actor power in the restitution processes of forests in three European countries in transition. Forest Policy and Economics 2020, 113, 102090. 